Doi: $\underline{\text { dx.doi.org/10.17921/2525-5320.2016.99-112 }}$

\title{
FORMAÇÃO DE PROFESSORES: FIOS DE UMA EXPERIÊNCIA SINGULAR
}

\author{
Cyntia Simioni França - UNOPAR ${ }^{\star}$ \\ Okçana Battini - UNOPAR*
}

Palavras-chave: Formação Continuada de Professores. Diversidade. Afrodescendentes.

\section{INTRODUÇÃO}

Neste artigo compartilhamos uma experiência singular de uma proposta de formação continuada de professores vinculada ao projeto de pesquisa "Professor, seu lugar é aqui" constituído por professores do Programa de Mestrado em Metodologias do Ensino, Linguagens e suas Tecnologias da Universidade Norte do Paraná (Unopar), pesquisadores e alunos de iniciação científica.

Primeiramente, o projeto tem como uma das preocupações refletir sobre os processos de formação continuada dos professores da rede pública de educação, na cidade de Londrina, no estado do Paraná. Ao longo de 2014 e 2015 estabelecemos uma parceria com o Colégio Estadual Barão do Rio Branco, sediado na cidade de Londrina, Paraná, para o desenvolvimento das atividades do projeto que possibilitou à Universidade ficar mais próxima do chão escola, por meio da construção de formação continuada, no local de trabalho do professor, partindo das experiências dos professores, das dificuldades e necessidades em relação à suas práticas de ensino.

Para conhecer os professores, as suas expectativas frente ao projeto formativo e as suas dificuldades e necessidades no espaço escolar, convidamos a participarem de um questionário com questões abertas e fechadas, pautado nos eixos: formação pessoal, inicial e continuada; trabalho docente e cotidiano e metodologias de ensino e tecnologias, pois acreditamos que as experiências vividas por esses profissionais fornecem indicativos para construirmos formações mais inventivas, criativas e significativas tanto para os professores como para os

*E-mail: cyntiasimioni@yahoo.com.br

*E-mail: okibattini@gmail.com 
pesquisadores que participavam do projeto.

Primeiramente, mapeamos as necessidades formativas dos professores que atuam na escola mencionada, no segundo momento do projeto, construímos junto com os professores essa proposta de formação continuada que será compartilhada nesse texto. Portanto, foram entregues 76 questionários para professores de diferentes áreas do conhecimento, porém, apenas 56 professores deram a devolutiva.

Decidimos fazer um recorte para esse artigo e tratar apenas da segunda etapa do projeto que focou o eixo sobre formação continuada de professores. Quando perguntamos sobre as suas necessidades acerca de propostas de formação continuada. Encontramos na maioria das respostas dos professores (55\%), o interesse em aprofundar o debate sobre a temática diversidade. Enquanto que (45\%) apontaram questões voltadas para suas áreas específicas e tecnologias de informação e comunicação.

Foi a partir da sistematização desses dados que o projeto Professor, seu lugar é aqui visou construir propostas de formação dialogando com os professores sobre a diversidade e desenvolvendo oficinas, palestras, teatro e outras atividades acerca da temática. Tivemos a participação efetiva de apenas 30 professores, acreditamos que de fato foram aqueles que apontaram a importância do processo formativo envolvendo a diversidade.

Trazíamos conosco o desejo seja como pesquisadoras e também professoras da educação básica refletirmos com outros colegas de trabalho, na escola mencionada, alternativas docentes. Alternativas que pudessem ser construídas face às contradições vivenciadas pelos professores da educação básica com seus alunos e comunidade escolar no que tange aos relacionamentos conflituosos, principalmente no que diz respeito à intolerância as diferenças étnicas. Portanto, durante o desenvolvimento do projeto formativo "Professor seu lugar é Aqui" buscamos junto com os professores encontrar práticas docentes dissonantes das tendências prevalecentes nos espaços escolares que pudessem contribuir para a construção de relações sociais mais humanizadoras entre aqueles que engendram o ambiente escolar.

\section{DISCUSSÃO}

Neste artigo, optamos rememorar a experiência singular do projeto formativo, 
situando para o leitor o arsenal teórico-metodológico que norteou as discussões durante os três ciclos de debates realizados junto com os professores, semanalmente, durante seis meses.

A primeira aproximação de diálogo com os professores foi compreender do que se trata quando falamos de diversidade e assumimos a concepção de que é uma construção histórica, social, cultural e econômica das diferenças, construídas nas relações de poder e sociais. Fundamentamos teoricamente a temática, a partir do pensamento de Nilma Gomes (2016) que entende a sociedade em que vivemos como desigual e com uma vasta diversidade: cultural, étnica, racial, de gênero, que se constrói imbricada nas relações de poder, das quais podem hierarquizar e discriminar a diversidade. É justamente a "contrapelo" das tendências hieraquizadoras e excludentes, prevalecentes na modernidade capitalista $^{1}$ que buscamos nortear o diálogo com os professores para que possamos contribuir para mudanças acerca da temática no espaço escolar (BENJAMIN, 1985).

Ainda no primeiro ciclo de debates com os professores, ressaltamos a importância dos movimentos sociais de cunho identitário que trouxeram à tona a diversidade como o direito à diferença para a nossa sociedade. Movimentos que problematizaram as questões socioeconômicas, a fim de compreendermos que as mesmas são insuficientes para entendermos o nosso país e construirmos justiça social. Considerando essa questão, passamos a levantar com os professores, quais os movimentos que engendravam essa luta e identificamos em nossa pesquisa de dados sobre o assunto, que são movimentos que vão desde as ações dos movimentos negros, dos indígenas, das mulheres, das pessoas com deficiência, dos LGBT (GOMES, 2016).

Pudemos perceber que tais movimentos problematizaram o lugar

subalterno em que algumas diferenças - no complexo contexto da diversidade - têm sido historicamente colocadas e como os sujeitos dos coletivos sociais que as expressam são considerados desiguais, inferiores e no limite do não humanos. Esse olhar problematizador trouxe desconforto para muitos setores da sociedade, explicitou relações de poder que hierarquizavam relações, indagou discursos antes vistos como verdades e

\footnotetext{
${ }^{1}$ Consideramos a modernidade capitalista está ligada aos aspectos concernentes à modernização das forças produtivas e dos valores estéticos, dificultando a fusão das forças materiais e espirituais dos sujeitos em nossa sociedade. Nesse sentido, partimos da leitura de Walter Benjamin (2006b) que aponta a necessidade de pensarmos de forma alargada a concepção de modernidade capitalista, tornando essencial a inclusão da dimensão cultural e a percepção das sensibilidades para o entendimento da realidade social, no que tange à busca pela superação das tendências instrumentais que desconsidera o fazer dos sujeitos no desenvolvimento social.
} 
apontou novos caminhos (GOMES, 2016, p. 278).

Com isso, compreendemos a relevância da implementação das políticas de ações afirmativas na sociedade brasileira na relação com as preocupações políticas bem como acadêmicas nos dias de hoje no que tange a questão das "minorias". Referimos às "minorias" a posição subordinada de um grupo dentro da sociedade ou ainda aqueles que vivem em uma situação de desamparo na sociedade. Segundo Giddens (2010) as minorias são os grupos que sofreram e ainda sofrem preconceito por aqueles pertencentes a sociedade dominante (majoritária).

Ainda em nossas discussões durante os encontros com os professores, levantamos a trajetória do surgimento das Políticas de Ações Afirmativas e identificamos que os Estados Unidos, nos anos 1960, apresentou a primeira proposta dessa política pública, resultante de reivindicações democráticas (CESAR, 2004). As ações afirmativas americanas requeriam que os

\begin{abstract}
empregadores adotassem medidas para acabar com as práticas discriminatórias da política de contratação de pessoal e, dali em diante, vinculasse todas as decisões sobre emprego numa base em relação à raça. Por isso, expandiu-se à ideia de que não bastavam as desigualdades sedimentadas pela escravidão e pela segregação oficial apenas com medidas não-discriminatórias. Era preciso também combater as consequências estruturais acumuladas com a discriminação. Assim, caberia ao Estado não só compensar os grupos prejudicados pelas discriminações passadas, como também criar possibilidades para prevenir que novas políticas de exclusão social fossem implantadas (CESAR, 2004, p.11).
\end{abstract}

As ações foram concebidas nos EUA como forma de enfrentamento da desigualdade das minorias étnicas, com relação à religião, de gênero ou de origem nacional. Uma vez consolidadas tais ações na esfera pública, as políticas afirmativas foram sendo aplicadas também nas universidades.

Mais tarde, as ações afirmativas se estenderam em muitos países como a Índia, na Nigéria, na Malásia e chega ao Brasil em 2001. Os programas atendiam as pessoas com baixa condição socioeconômica, apesar da busca de tentativas de implementação de tais ações desde 1990, em órgãos públicos. (SOWELL, 2004),

Na mesma década, com a Conferência Mundial sobre Educação Para Todos a educação para os países pobres passou a ser entendida como equidade social. Também a Unesco e a Cepal têm lutado para que os governos nacionais implantem políticas educativas. Fruto disso é o a implantação do projeto PRELAC que se constituiu a base de quatro princípios e cinco focos estratégicos que surgem como 
propostas políticas, dentre os princípios: ruptura com enfoques neoclássicos; produção do conhecimento, promoção da diversidade; dever da sociedade a educação.

Para o Estado liberal burguês, a lei deve ser igual para todos, portanto, bastaria a inclusão da igualdade efetivamente assegurada na constituição. No entanto, essa concepção começou a ser vista com outros olhos quando se verificou que a igualdade de direitos não era suficiente para que todos tivessem as oportunidades dos indivíduos privilegiados socialmente.

Sendo assim, o que de fato importaria, seria possibilitar que os grupos minoritários fossem colocados no mesmo nível de igualdade de condições daqueles privilegiados economicamente na sociedade.

Portanto, o público-alvo das ações afirmativas em nosso país abrange os negros, os índios, as mulheres, as pessoas envolvidas com as questões de gênero, os idosos, as pessoas com necessidades especiais, os marginalizados economicamente. Sendo as áreas contempladas o mercado de trabalho, o sistema educacional e a esfera política.

Essas definições introduzem a ideia da necessidade de buscar ações na busca de minimizar a desigualdade, ou seja, oferecer um tratamento próprio para grupos minoritários, cuja particularidade ou diferença é travada historicamente de forma desigual. Sendo assim, uma das propostas da ação afirmativa é coibir a discriminação no presente, mas, sobretudo, eliminar os efeitos persistentes da discriminação do passado que tendem a se perpetuar em nosso país, por meio de práticas culturais e nos discursos sociais. Tendo em vista que a igualdade e a liberdade nunca foram consumadas para todos que aqui vivem, visto que as práticas discriminatórias e o tratamento desigual continuam ainda sendo predominante nas relações existentes em nossa sociedade. (GOMES, 2001)

Tal situação é muito visível nas escolas† públicas do nosso país, a historiadora Claudia fortuna explica que o passado é ensinado como homogêneo, com o intuito de modelar um cidadão patriótico e as personalidades da nossa história ficam

restritos à elite branca. Neste cenário, os alunos são estimulados a aprender que o povo brasileiro é formado por brancos descendentes de portugueses, índios e negros e que deve prevalecer a ideia de ausência de preconceitos raciais no interior de uma sociedade sem conflitos. Na constituição desta memória histórica, aos negros cabem poucas páginas, ora como escravo,

\footnotetext{
† Esse fato vivenciamos ao longo da nossa experiência docente na escola pública.
} 
ora como vencido, ora com sua cultura transformada em folclore (FORTUNA, 2008, p.52).

Esse fato nos ajudou a compreendermos como o processo de divisão de culturas reflete na inserção dos sujeitos na sociedade vigente e como a história é ensinada aos alunos em muitas das escolas públicas ou privadas do país, contribuindo para a construção de uma memória dominante.

Será possível ir ao encontro do que foi esquecido ou apagado da historiografia dominante? É possível superar a hierarquização de culturas na modernidade? A partir, das duas questões centrais apontadas, desdobraram-se calorosos debates com os professores durante os encontros realizados na escola, principalmente, que o racismo é fruto da divisão de culturas e das relações étnico-raciais que impõe a necessidade das minorias se organizarem contra a perpetuação da hierarquização da sociedade.

Buscamos para subsidiar o debate, o filósofo alemão Walter Benjamin, (1985, p. 224-225) que nos orienta da importância de despertar no presente as "centelhas da esperança", visto que nem os mortos "estarão em segurança se o inimigo vencer. E esse inimigo não tem cessado de vencer". O autor insiste sobre os ancestrais vencidos, pois considera que

\begin{abstract}
não há luta pelo futuro sem memória do passado, a memória viva e concreta dos ancestrais martirizados. Não se trata de uma rememoração que leve à lamúria, à melancolia, ao ódio ou vizinhança, mas de uma rememoração como fonte de energia para as lutas do presente. Pela rememoração, o passado permanece aberto. E são as lutas que acontecem no presente que colocam em cheque as vitórias históricas dos vencedores, enfraquecendo o poder dos opressores, tanto do passado como dos tempos atuais (FORTUNA, 2008, p.56).
\end{abstract}

A história da sociedade brasileira não está redimida se continuarmos com o mesmo olhar, com as resistências em relação as possibilidades de construção de "outra" história e nos impede de reconhecemos o processo escravocrata e seus resquícios nos dias de hoje.

Além disso, para que essa história seja libertada, ou ainda arrancada do conformismo, é de extrema urgência escovar a história a contrapelo das tendências das ideologias burguesas. Não há possibilidade de políticas de ação afirmativa se não repensar a sociedade em um contexto mais amplo em relação ao passado e com vistas a projeção futura. O que implica olhar para o passado como uma necessidade de escutar às "vozes silenciadas", o voltar ao passado não apenas para 
conhecê-lo tal como ele foi, mas, para agir no presente. (BENJAMIN, 1985)

Ao encontro do debate Marcel Proust (1946) enfatiza que ao buscar mudanças não é necessário encontrar novas paisagens, mas simplesmente olhar com olhos "novos". Possibilitando que uma cesura aconteça no continum da história. Nesse sentido refletimos como as políticas afirmativas podem trazer à tona as memórias que ora foram silenciadas ou escamoteadas, ou seja, rememorar a história em busca de outro por vir.

Esse é o apelo de Walter Benjamin (1985), juntar os "cacos, os estilhaços, e as ruínas" produzidos pelas catástrofes do passado a fim de reconstituir o que foi arruinado e apagado pelas ideologias dominantes. Ao reunir os fragmentos do passado, buscamos um redimensionamento do presente e encontrar possibilidades outas de futuro que podem contribuir para romper com a desigualdade, o preconceito, a exclusão, os privilégios que permanecem e perpetuam no país.

\section{Em busca da história dos afro-descendentes}

Após o primeiro ciclo de debate que focalizou a temática diversidade e a relação com as políticas das ações afirmativas, no segundo ciclo de diálogos, priorizamos as questões que envolvem os afro-brasileiros. Com essa delimitação temática, problematizamos com os professores como o preconceito e a discriminação chegam em nossas salas de aulas e se é possível atuar a "contrapelo" das tendências homogeneizadoras. Ao final dos questionamentos e das afirmativas acerca das possibilidades de mudanças em nossas práticas de ensino, entendemos primeiramente que para "compreender e superar o racismo, é preciso mais do que reconhecimento. É necessário saber as diferentes formas como ele opera, qual é a sua relação com as desigualdades e como esse fenômeno afeta o processo de construção das identidades". (GOMES, 2016, p. 278)

Por isso, refletimos em alguns encontros com os professores sobre democracia multirracial e entendemos que não se pode pensar a democracia a partir dos moldes do

velho nacionalismo unificador, pois, dessa forma, se realizaria uma integração cultural imposta de cima para baixo e a cultura que se imporia seria a da classe dominante. $O$ processo de integração assim pensado supõe o embranquecimento generalizado do povo brasileiro, a perda da contribuição criadora que cada raça pode trazer. Fernandes (1972) não quer este embranquecimento, este desaparecimento do negro [...] quer que 0 negro se afirme e assuma sua diferença (VERTUAN, 2007, p.106). 
Assim, Florestan Fernandes (1972) contribuiu para um debate fértil com os professores sobre o desmascaramento do mito da democracia racial que busca perpetuar a ideia do negro ainda como escravo (mercadoria/inferior) para manter a hierarquia da convivência. O autor ressalta que o negro e sua cultura, sempre participaram do processo de desenvolvimento do país, mas sempre em posição de inferioridade dentro da estrutura social, visto que no inicio do processo de colonização eram vistos como mercadorias e depois da abolição da escravidão, em 1888, a presença do negro sempre foi vinculada ao trabalho não capacitado. Porém, o negro sempre esteve presente no processo de construção da sociedade brasileira e sua participação ajudou a construir os padrões culturais do povo brasileiro. Mas a sociedade, historicamente e ideologicamente, colocou o negro a margem do processo social, visto que com o desenvolvimento das relações de trabalho assalariado nas cidades, os negros passaram a concorrer com os trabalhadores imigrantes, que já estavam acostumados com o trabalho estipulado pelo modo de produção capitalista (BATTINI, 2011)

Mas é fato que a ideia de inferioridade do negro é uma justificativa apenas para perpetuar o preconceito. Embora ocorreram mudanças no sistema político e social brasileiro, porém, ainda permanece no imaginário coletivo o passado escravocrata, principalmente na mentalidade daqueles que determinam as relações raciais. Ou seja, embora os negros não são mais escravos, ainda continuam para muitos vistos como seres "inferiores". (FLORESTAN, 1972)

Para o autor a manutenção das estruturas arcaicas é considerada uma anomalia da sociedade, pois o preconceito e a discriminação racial perpetuam a desigualdade racial de forma incompatível com o desenvolvimento da sociedade competitiva. Além disso, contradiz com os fundamentos

jurídicos da democracia. Quando a ordem tradicional escravista se desagrega, surgindo a sociedade de classes, o preconceito e a discriminação racial, deixando de ter função, deveria desaparecer. Entretanto, eles permanecem arraigados na sociedade de classes. O preconceito é apenas outra manifestação do mito da democracia racial no qual é o próprio preconceito que se esconde para manter o passado no presente. Incompatível com os ideais democráticos da nova sociedade e com o desenvolvimento do regime de classes, desprovido de função aparente, o preconceito passa a ser negado, relegado ao inconsciente (VERTUAN, 2007, p.107). 
A discussão sobre o mito da democracia racial possibilitou aos professores relatarem durante os encontros que muitas das nossas crianças estão frequentando a escola e assumindo outras identidades, a fim de minimizar os constrangimentos que passam em sala de aula. O relato das experiências entre os professores foi de suma relevância para reconhecermos, o quanto os movimentos sociais são de suma importância, bem como mecanismos de luta para a garantia dos direitos sociais e a busca da igualdade. Assim, especificamente, o Movimento Negro no Brasil, reivindica melhoria na vida da população negra no Brasil, assume a bandeira de combate ao preconceito e o racismo tão presente em nossa sociedade. Além disso, foi possível perceber o quanto as Ações Afirmativas são políticas públicas essenciais em nosso país, pois além dos constrangimentos vividos por nossos alunos nos espaços escolares, ainda chamamos a atenção para um fato importante: infelizmente há uma invisibilidade por parte dos educadores sobre o racismo, ou uma negação dessa desigualdade racial no espaço escolar. Problematizamos esse fato, com os professores participantes do projeto, trazendo o relato de uma pesquisa-ação, desenvolvida em escolas, na cidade de São Paulo pela pesquisadora Ana Maria Niemeyer, em que a autora relata que muitos professores negam a existência do racismo e que existe muita desinformação dos educadores e muitas vezes

[...] diante de algum preconceito, de uma discriminação e até de uma situação racista, os professores ficam calados porque não sabem como identificar aquela atitude e, portanto, como discuti-la com a classe. Outras vezes se omitem porque não estão acostumados a pensar no significado de comportamento como esses na auto-estima de seus alunos. Também existem aqueles que se calam porque são racistas. E aqueles que se manifestam pelas mesmas razões (NIEMEYER, 2002, p.46-47).

Fomentarmos ainda mais o debate com os professores acerca da invisibilidade e omissão dos professores diante de práticas racistas com relatos de nossa experiência, vivida uma escola pública, na cidade de Londrina, no estado do Paraná, durante a nossa participação como membros de uma mesa redonda que tratava sobre a Lei 10.639/03 (uma das Ações Afirmativas-Lei do Ensino da História e Cultura Afro-Brasileira e Africana de inclusão nos currículos dos estabelecimentos de ensino fundamental e médio conteúdos relacionados à História da África e à Cultura Afro-Brasileira). Quando encerramos as nossas falas abrimos para o diálogo com os professores e então, vieram à tona nas discussões dos educadores, as 
resistências, os conflitos e as contradições sobre como pensam a questão da diversidade. Muitos deles não entendem que a lei busca trazer outras versões no processo didático-pedagógico das histórias da população afro-descendente, já que não consideram a existência de racismo na escola e nem mesmo pertinente pensar de maneira mais ampliada tal lei, nas práticas de ensino.

Os relatos apresentados geraram o interesse para construirmos o terceiro ciclo de debates com os professores, debruçando as leituras para a Lei 10.639/03 e a sintetizarmos as nossas discussões dialogando com o pensamento da historiadora Claudia Fortuna, quando menciona que o documento foge de alguns eixos argumentativos predominantes que compreende a existência de vários fios de avanços.

\begin{abstract}
Existe uma visão de história que se propõe a focalizar a dimensão cultural das experiências dos negros, historicamente dadas na relação com o social. $\mathrm{Na}$ questão de formação de professores, as Diretrizes confirmam, para além da qualificação necessária nas áreas de conhecimento, a importância de pessoas sensíveis e capazes de direcionar positivamente as relações entre pessoas de diferentes pertencimentos, étnico-raciais e insiste na desalienação dos processos pedagógicos. Contrário à difusão em massa dos conhecimentos feitos mercadorias, o documento considera que escola tem o dever de se posicionar politicamente por meio de questionamentos e análises críticas sobre conceitos, ideias e comportamentos veiculados pela ideologia dominante e pelo mito da democracia racial. As políticas pretendidas apontam para as mudanças dos discursos, raciocínios, lógicas, gestos, posturas e os modos de se tratar pessoas negras. O texto aponta a importância da sensibilidade e de uma consciência política e histórica da diversidade. (FORTUNA, 2005, p.94).
\end{abstract}

O que implica pensarmos que não se trata de mudar o viés etnocêntrico para outro africano, mas dilatar o currículo, de modo que não se contemple simplesmente conteúdos históricos que envolvem essas questões, mas exige repensarmos as relações étnico-raciais de forma ampliada, como uma mudança de mentalidade, a fim de que a História dos povos afro-descendentes articule com as dimensões temporais: passado, presente e futuro, no âmbito das experiências nas diferentes realidades do povo negro.

A historiadora Marcia Bichara (2005) também chama a atenção para extrapolarmos noção mais dilatada sobre preconceito e a discriminação, pois ambos não podem simplesmente ser explicados, a partir da questão étnica, mas como práticas que envolve também os preceitos da modernidade capitalista. Por esse fato, é necessário compreendermos como se dão as relações entre as pessoas numa sociedade capitalista, injusta, competitiva e excludente que leva ao desenraizamento 
dos sujeitos de suas histórias e experiências vividas. Porém, também encontramos imagem ambivalentes da sociedade, pois ao mesmo tempo encontramos pessoas "lutando para construção de solidariedade e a constituição de sujeitos autônomos e construtores de relações sociais mais inteiras e mais intensas" (BICHARA 2005, p.21)

Ao final dos três ciclos de debates com os professores compreendemos que apesar das contradições da modernidade capitalista acerca da diversidade, ainda assim, podemos operar pelas brechas para que relações "outras" possam ser construídas no futuro e os caminhos estão abertos para outros modo de viver mais humanizadores no espaço escolar.

\section{CONCLUSÃO}

A experiência que vivemos nesse projeto formativo "Professor: Seu Lugar é Aqui" nos colocou diante de novas possibilidades e desafios como o de nos reconhecermos como sujeitos históricos, capazes de construir uma nação igualitária e mais democrática. Acreditamos que podemos contribuir, enquanto docentes, para tal discussão, operando nas brechas dos espaços educacionais, em prol de buscar eliminar por meio de nossas ações docentes, atos preconceituosos/discriminatórios no diálogo com nossos alunos, visando construir um mundo menos opressivo, desigual e injusto.

Vale ressaltar que a escola reluz imagens ambivalentes, pois pode ser espaço de reprodução de ideologias dominantes, mas também lócus de mudanças sensíveis, no que tange as questões racistas e isso, depende dos sujeitos que ocupam o espaço escolar. Acredito que encontraremos professores, alunos, equipe pedagógica e também pais que estão dispostos a construir relações mais solidárias.

Ainda que sabemos que os negros foram e são vítimas da dinâmica dos movimentos do sistema capitalista, porém, entendemos que também são agentes transformadores da sua história, no tempo presente. A lei 10.639/03 com repercussões na base-pedagógica, inclusive no que tange a formação de professores pode oferecer um impulso para que os professores e alunos sejam produtores do conhecimento.

A partir dessa experiência vivida, nós pesquisadoras, percebemos que os encontros realizados possibilitaram aos professores compreenderem historicamente o engendramento dos preconceitos e da discriminação nos dias de hoje e puderam 
por meio dos debates com as pesquisadoras, com os colegas de trabalho bem como a partir do diálogo com o referencial teórico-metodológico entender a complexidade das práticas excludentes no cotidiano escolar e na sociedade de modo mais amplo. Foi perceptível pela fala dos professores que muitos não tinham noção da amplitude das relações desumanizadoras que instituem a sala de aula e assim, nos relataram que a partir dos ciclos de debates, passaram a atentarem-se para suas práticas de ensino e deterem, mais especificamente, para suas próprias atitudes, a fim de que também reconheçam e compreendam que relações têm construído, e mantido em sala de aula bem como praticada com seus alunos e a comunidade escolar de um modo mais amplo.

Nessa segunda fase do projeto que foi rememorada nesse artigo, preocupamos durante os encontros fortalecer a dimensão humana do professor e ampliar a noção de sujeito histórico para que possam construir práticas de ensino dissonantes das tendências prevalecentes da modernidade e assim, construam relações sociais mais humanas. (GALZERANI, 2008)

Enfim, fica o convite para nós, enquanto professores, interrompermos o percurso do continum da história para salvar a sociedade das ideologias dominantes e assim, escovar a "história a contrapelo", como diria Benjamin (1985). O que implica pensar na reconstrução das relações étnico-raciais no campo educacional, sem dissociar o sentir, o pensar e o agir dos sujeitos que ocupam esse espaço bem como romper com a barreira que impede a relação entre o "eu" e o "outro". Benjamim (2007) nos direciona pelos caminhos das ruínas, recolhendo os cacos no presente. "O colecionador/historiador quer salvar na sua arca" o máximo possível de ruínas da tempestade, do seu destino desprezível, ocultado pela história oficial. Portanto, ainda há história para ser escrita, uma história silenciada que está à espera do presente e de todos para ser transformada. Um sonho possível?

\section{REFERÊNCIAS}

BATTINI, O. Multiculturalismo e identidades. Londrina: Unopar, 2011.

BENJAMIN, W. Sobre o conceito da história. São Paulo: Brasiliense, 1985.

BENJAMIN, W. Passagens. Belo Horizonte: UFMG, 2007.

BENJAMIN, W. O narrador. São Paulo: Brasiliense, 1985.

BENJAMIN, W. Experiência e pobreza. São Paulo: Brasiliense, 1985. 
BICHARA, M.R.P. Focando a discriminação em sala de aula: memória, história e ensino de história. Dissertação (Mestrado em Educação) - Universidade Estadual de Campinas. Campinas, 2005.

BICHARA, M.R.P.; GALZERANI, M.C.B. Discriminações em sala de aula: memórias, histórias e ensino de história. In: ZAMBONI, E. et al. Memórias e histórias da escola. Campinas: Mercado de Letras, 2008. p.149-172.

BRASIL. Constituição (1988). Constituição da republica federativa do Brasil. São Paulo: Saraiva,1991.

BRASIL. GTI-MEC. Contribuições para implementação da lei 10.639/03, Brasília2008.

Disponível

em: <http://www.brasilia.unesco.org/publicacoes/pdf/Contribuicoes/mplementLei10.639.p df>. Acesso: 27 set. 2015.

BRASIL. Lei $n^{\circ}$ 10.639, de 9 de janeiro de 2003. Diário Oficial [da] República Federativa do Brasil. Brasília, DF, 9 jan. 2003. Disponível em: <http://www.planalto.gov.br/ccivil_03/leis/2003/L10.639.html>. Acesso: ago. 2015.

BRASIL. Parâmetros Curriculares Nacionais: História e Geografia. Brasília: MEC/SEF, 1998.

BRASIL. Ministério da Educação. Parâmetros Curriculares Nacionais: pluralidade cultural, orientação sexual. Brasília: MEC/SEF, 1997.

CANEN, A.; MOREIRA, AF.B. Reflexões sobre o multiculturalismo na escola e na formação docente. In: CANEN, A.; MOREIRA, A. F. B. (Org.). Ênfases e omissões no currículo. Campinas: Papirus, 2001.

CESAR, R.C. Ações afirmativas no Brasil: e agora doutor? Ciência Hoje, v.33, n.195. 2004.

DECLARAÇÃO DE SALAMANCA. Necessidades Educativas Especiais - NEE In: Conferência Mundial sobre NEE: Acesso em: Qualidade - UNESCO. Salamanca/Espanha: UNESCO, 1994.

FERNANDES, F. A integração do negro na sociedade de classes. São Paulo: Dominus, 1972.

FORTUNA, C.R.A.P. Fios de histórias e memórias dos africanos e afrodescendentes no Brasil moderno. Por uma educação política dos sentidos. Campinas, Tese (Doutorado em Educação) - Faculdade de Educação. 2008

GALZERANI, M.C.B.; PARDO, M.B.L.; LOPES, A. (Org.). Una "nueva" cultura para la formación de maestros: es posible? Porto: Livipsic/AMSE-AMCE-WAER, 2008.

GIDDENS, A. Sociologia. Lisboa: Fundação Calouste Gulbenkian, 2010. 
GOMES, J.B.B. Ação afirmativa e princípio constitucional da igualdade: o direito como instrumento de transformação social. Rio de Janeiro: Renovar, 2001.

GOMES, J.B.B. O debate constitucional sobre as ações afirmativas. 2002. Disponível em: <www.mundojuridico.adv.br>. Acesso em: 15 set. 2015.

GOMES, N.L. Cotas para a população negra e a democratização da universidade pública. In: PEIXOTO, M.C.L. (Org.). Universidade e democracia. Belo Horizonte: UFMG, 2004.p.45-56.

GOMES, N.L. Diversidade e afrodescendência: mediações, interações e (re)conhecimento. Comunicação em Foco, v.18, n.26, p.277-280, 2015.

NIEMEYER, A.M. O silenciamento do 'negro' na auto-identificação étnica: um estudo com adolescentes de duas escolas públicas paulistanas. O silenciamento do 'negro' na auto-identificação étnica: um estudo com adolescentes de duas escolas públicas paulistanas. NUDECRI/UNICAMP, v.8, p.43-72, 2002.

NOGUEIRA, J.K.; FELIPE, D.A; TERUYA, T.K. Conceitos de gênero, etnia e raça: reflexões sobre a diversidade cultural na educação escolar. In: SEMINÁRIO INTERNACIONAL FAZENDO GÊNERO. 8, 2008, Florianópolis. Corpo, Violência e Poder, 2008.

SOWEL, T. A ação afirmativa ao redor do mundo: um estudo empírico. Rio de Janeiro: UniverCidade, 2004.

VERTUAN, M.J.S. História afro-brasileira e africana nas escolas. In: ANDREI, E.M.; FERNANDES, F.A.G. Cultura afro-brasileira: construindo novas histórias. Caderno Uniafro 2. Londrina: Idealiza, 2007. 